\title{
A Study of the New Environmental Paradigm Scale in the Context of Iran
}

\author{
Fahimeh Hosseinnezhad ${ }^{1 *}$
}

${ }^{1}$ Hacettepe University, Turkey

*Corresponding Author: hosseinnejad64@gmail.com

Citation: Hosseinnezhad, F. (2017). A Study of the New Environmental Paradigm Scale in the Context of Iran. European Journal of Sustainable Development Research, 1(2), 14. doi: $10.20897 /$ ejosdr.201714

Published: June 30, 2017

\begin{abstract}
Industrial and technological change and increased urbanization has altered the face of nature. And nature is being consumed in the production of material goods. Environmental crises such as the condition of Lake Urumieh in north western Iran demonstrates that unregulated use of the natural environment disrupts ecosystems that threaten the survival of plant species, animals and humans. Environmental crises can be facilitated by human's inappropriate activities that occurs as the result of people's attitude to the environment. The aim of this paper is a revision of the New Environmental Paradigm and an evaluation on the NEP scale of the citizens of Tabriz. Results of exploration of related factors determined four dimensions, while evaluations determined by the Dunlap and Van Liere scale showed five dimensions. Average for the factor of citizen attitude in protecting the environment was determined as moderate. Also, there was difference for averages for the factor of citizen attitude to the environment according to gender. Results showed that women had a more supportive attitude than did men. The relationship between factors of education and economic prosperity to the environmental attitude is being shown a more supportive attitude to the environment under conditions of higher-level education and economic prosperity. Regression analysis showed that education explains approximately eleven percent of variance in terms of environmental attitude.
\end{abstract}

Keywords: environmental attitude, new environmental paradigm scale, education

\section{INTRODUCTION}

The environment has a longstanding and important place in human history. Human beings have always looked to nature to meet their physical needs and spiritual desires. Today sociologists, economists, philosophers and psychologists pay special attention to the environment and it seems that the environment is a point of common interest among a variety of human discourses.

Environmentalism as a political and social movement emerged during the late 1960s and the early 1970s. The first broad environmental discourse was the growth debate that started in 1972 with the Club of Rome report "Limits to Growth" (Huber, 2002: 2). For the purpose of environmentalism sociologists have begun to study the relationship between society and the environment and more specifically the effect of these societies in terms of environmental protection or destruction. Economists have focused on the relationship between the economy and the environment and psychologists consider the relationships between individual human characteristics and the environment. So the environment has become an important consideration in human sciences.

In recent decades, however, environmental problems have evolved in significant ways. Although localized pollution, especially hazardous waste, continues to be a major issue, environmental problems have generally tended to become more geographically dispersed, less directly observable and more ambiguous in origin. Not only do 
problems such as ozone depletion, deforestation, loss of biodiversity and climate changes cover far wider geographical areas (often reaching the global level), but their causes are complex and synergistic and their solutions complicated and problematic (Stern et al, 1992; Dunlap et al, 2000). Researching interested in understanding how the public sees environmental problems are gradually paying attention to these newly emerging "attitude objects" (Stern et al, 1995: Dunlap et al, 2000).

Exploring attitudes is important because generally it is believed that attitude has a direct influence on human behavior and activity. Fishbein and Azjen (2005) distinguish between two types of attitude. The first type is general attitudes toward physical objects such as racial, ethnic, or other groups, institutions, policies or other general targets. The second type is attitudes toward performing specific behaviors with respect to an object or target. These attitudes will be referred to as attitudes toward a behavior.

The oldest and simplest models of pre-environmental behaviors were based on a linear progression of environmental knowledge leading to environmental awareness and concern (environmental attitude), which in turn was thought to lead to pro-environmental behavior (Kollmuss and Agyeman, 2002: 241). This research is being aimed at revision of the NEP scale based on an exploratory factor analysis and examination of the attitudes to the environment of the citizens of Tabriz according to the New Environmental Paradigm (NEP). The study also aimed to evaluate the relationship of environmental attitudes with the variables of gender, education and economic prosperity.

Dunlap et al (2000) expressed that NEP scale has been widely used during the past two decades. It has been used more often with samples of the general public, but it has also been used with samples of specific sectors such as farmers and members of interest groups. It has been used as well to examine the environmental orientations of ethnic minorities in the United States, as well as of resident of other nations such as Canada, Sweden, the Baltic States, Turkey and Japan.

According to Anderson (2012) the New Environmental Paradigm scale will continue to be used widely. Because no other instrument has been so extensively accepted as a measure of environmental world views, it will continue to be valuable, if for no other reason that it gives researchers comparisons to make across study types, population types and time, the growing body of research will create additional opportunities to test the NEP for its reliability and validity.

The first step was to revise items and dimensions of the NEP to consider the context of Iran. There is a lot of environmental issues in Iran. In urban areas excessive emissions pollute air, refinery operations and industrial effluents also contribute to poor air quality. Tehran is one of the world's most polluted cities and Tabriz, Shiraz, Mashhad and Isfahan are rated as the most polluted cities in Iran. Air pollution, water shortage, water pollution, drought, soil degradation, sandy wind and drying Lake Urumieh in the north western Iran causes salty wind that threat the lives of millions of people. Iran has been practicing poorly to prevent environmental damage and as a result there are many healthy problems. Tabriz as an industrial city also has many environmental problems that threat the well-being of people.

Despite the looming shortages, Iranians do not manage water efficiently. Domestic use of water resources in Iran is about $70 \%$ more than the global average. Air pollution is another major problem. Over the past several years, Iran has also been suffering from increasingly severe dust and sandstorms. These are especially impacting western provinces bordering Iraq, from where the storms mainly originate (Slavin, 2013).

Despite many environmental problems rising environmental consciousness in Iran, particularly among educated people will be promising. People's sensitivity to environmental problems could be the start of the path towards solutions. Attitude is a major factor in directing the behavior and lifestyle of individuals and understanding what people's attitude to environmental issues is, could determine the future of the environmental status in Iran. 'It has been believed that individual knowledge of any subject influences his/her behavior and performance towards that issue' (Maleki and Karimzadeh, 2011: 35).

\section{NEW ENVIRONMENTAL PARADIGM}

In the mid-1970s Dunlap and Van Liere argued that implicit within environmentalism was a challenge to our fundamental views about nature and human's relationship to it. Their conceptualization of what they called the New Environmental Paradigm (NEP) focused on beliefs about humanity's ability to upset the balance of nature, the existence of limits to growth for human societies and humanity's right to rule over the rest of nature (Dunlap et al, 2000: 427). Humphrey et al (2002) argued that there are five formative influences on the development of environmental sociology: human ecology, environmental movements, rural sociology, urban sociology and new environmental paradigm.

NEP rooted in attitude theory and primitive beliefs about the nature of the earth and humanity's relationship with it. According to Rockeach (1968) primitive beliefs form the inner core of person's belief system and represent his basic truth about physical reality, social reality and the nature of the self. Attitude theory (Ayzen and Fishbein, 
1980) share the idea that behavior is intentional or purposive and rooted in psychology, focus on how individuals make choices or decisions regarding a specific object or situation (Stets and Biga, 2003: 339). Catton and Dunlap (1978) use the Human Exemptionalism Paradigm (HEP) / New Environmental Paradigm (NEP) distinction to study the relationship between the human and environment. The HEP has four major assumptions:

1. Humans are unique among the earth's creatures, for they have culture.

2. Culture can vary almost infinitely and can change much more rapidly than biological traits.

3. Thus, many human differences are socially induced than inborn, they can be socially altered, and inconvenient differences can be eliminated.

4. Thus, also, cultural accumulation means that progress can continue without limit, making all social problems ultimately soluble.

They in contrast advance NEP, which critique of mainstream HEP sociological thought. The principal assumptions of the NEP included:

1. Human beings are but one species among the many that are interdependently involved in the biotic communities that shape our social life.

2. Intricate linkages of cause and effect and feedback in the web of nature produce many unintended consequences from purposive human action.

3. The world is finite, so there are potent physical and biological limits constraining economic growth, social progress and other societal phenomena (Catton and Dunlap, 1978: 45).

Up to now, many studies have examined environmental attitudes and the NEP scale. Reports on other related experiments Kopnina (2011) focused on examining 59 Dutch school children between the ages of 10 and 12 on the NEP scale. Results show that some items on the NEP scale were ambiguous revealing differences in terms of cognitive approach (knowledge) and affective states. Franzen and Mayer (2009) focused on environmental attitude in cross national perspective. They discuss Inglehart's theory of post materialism, Dunlap and Mertige's globalization explanation and the prosperity hypotheses. Results show individual with higher relative income display higher level of environmental concern and wealthier countries have more concern to environment than poorer countries, hence environmental concerns are closely associated with post materialistic attitude.

Tuna (2004) focused on environmental attitude in Turkey, as a developing country that environmental issues have taking more public attentions for last few decades. Therefore an environmental awareness has been emerging in Turkish public. In this research environmental attitude has three dimensions: worldview, concern and commitment. Results show environmental worldview has the highest score level and at least common form of environmental value. Environmental concern is moderate form and environmental commitment is at least common and the most specific form of environmentalism.

According to Usi et al (2003) the structure of environmental value in Asian countries differs from those in western countries. In Western countries altruistic values dominated. But in Asian countries environmental values are linked with both traditional and altruistic values. Kaiser et al (1999) suggested that environmental attitude is a powerful predictor of ecological behavior. Questionnaire data from members of two ideologically different Swiss transportation associations are used. This study confirmed three measures as orthogonal dimensions by means of factor analysis: environmental knowledge, environmental values and ecological behavior intention. Results showed that environmental knowledge and values explains approximately fourthly percent of variance in terms of ecological behavior.

According to Maleki and Karimzadeh (2011) there is a relationship between the environmental attitudes and environmental knowledge and energy consumption behavior in Urumieh, Iran. They used Dunlop's NEP scale for measuring environmental attitudes and Salehi's Items was employed for measuring environmental knowledge. The results are shown that; the participants owned positive environmental attitude, there was a statistically significant relationship between the environmental attitude and environmental behavior (energy consumption) of the participants, and there was not any statistically significant relationships between environmental knowledge-either systematic knowledge or behavioral knowledge-and environmental behavior of the participants.

\section{HYPOTHESES}

1. Gender has no difference on the average of evaluations for environmental attitude.

2. There is no significant relationship between education and attitude to the environment.

3. There is no significant relationship between economic property and attitude to the environment.

\section{Methodology}

This research is a survey, based on quantitative methodology. The research population consisted of residents of Tabriz aged over 15 years of age. The estimated population of the city was around 2,000,000 according to data from the Iranian census bureau. Tabriz is the fourth most populous city in Iran after Tehran, Mashhad, and 
Table 1. Exploratory Factor Analysis (dimensions of environmental attitude and NEP scale).

\begin{tabular}{|c|c|c|c|c|}
\hline Constructs & Items & $\begin{array}{l}\text { Factor } \\
\text { loading }\end{array}$ & $\begin{array}{l}\text { Explained } \\
\text { variance }\end{array}$ & $\begin{array}{l}\text { Total } \\
\text { Explained } \\
\text { Variance }\end{array}$ \\
\hline antianthropocentrism & $\begin{array}{l}\text { 1. Humans have the right to modify the natural } \\
\text { environment to suit their needs. } \\
\text { 2. Plants and animals have as much right as humans to } \\
\text { exist. } \\
\text { 3. Humans were meant to rule over the rest of nature. } \\
\text { 4. Despite our special abilities, humans are still subject } \\
\text { to the laws of nature. }\end{array}$ & $\begin{array}{l}0.78 \\
0.81 \\
0.72 \\
0.68 \\
\end{array}$ & 22.45 & \\
\hline Limits of growth & $\begin{array}{l}\text { 5. We are approaching the limit of the number of } \\
\text { people the earth can support. } \\
\text { 6. The earth has plenty of natural resources if we just } \\
\text { learn how to develop them. } \\
\text { 7. The earth is like a spaceship with very limited room } \\
\text { and resources. } \\
\text { 8. Humans will eventually learn enough about how } \\
\text { nature works to be able to control it }\end{array}$ & $\begin{array}{l}0.78 \\
0.76\end{array}$ & 17.86 & 60.53 \\
\hline $\begin{array}{l}\text { The possibility of an } \\
\text { ecocrisis }\end{array}$ & $\begin{array}{l}\text { 9. Humans are severely abusing the earth. } \\
\text { 10. The so-called "ecological crisis" facing humankind } \\
\text { has been greatly exaggerated. } \\
\text { 11.If things continue on their present course, we will } \\
\text { soon experience a major environmental catastrophe. } \\
\text { 12. Human ingenuity will insure that we do not make } \\
\text { the earth unlivable. }\end{array}$ & $\begin{array}{l}0.79 \\
0.74 \\
0.68 \\
0.62\end{array}$ & 11.84 & \\
\hline $\begin{array}{l}\text { The fragility of } \\
\text { nature's balance }\end{array}$ & $\begin{array}{l}\text { 13. When humans interfere with nature, it often } \\
\text { produces disastrous consequences. } \\
\text { 14. The balance of nature is strong enough to cope with } \\
\text { the impacts of modern industrial nations. } \\
\text { 15. The balance of nature is very delicate and easily } \\
\text { upset. }\end{array}$ & $\begin{array}{l}0.71 \\
0.63\end{array}$ & 8.37 & \\
\hline
\end{tabular}

Esfahan, it is also a major Iranian heavy industrial and manufacturing center. Industrial activity in Tabriz includes the production of automobiles, machine tools, oil and petrochemicals and cement. Tabriz is a large city and as such faces many environmental problems, which are predominantly related to over urbanization, air pollution, noise pollution, energy consumption, a shortage of green space, domestic and industrial waste and carbon emissions. Tabriz has historically been a garden city. Recently, the citizens of Tabriz have been protesting the state of Lake Urumieh in an attempt to save the lake.

The sample size the study was 682 people. The sampling model was multi-stage stratified.

\section{Factor Analysis of NEP Scale}

Environmental attitude: Environmental attitude is measured by 15 items in the Likert scale. Items coded 1 to 6 scale $(1)=$ strongly disagree. $(2)=$ disagree. $(3)=$ somewhat disagree. $(4)=$ somewhat agree. $(5)=$ agree. $(6)=$ strongly agree. The recorded response categories indicate that (1) is lowest level of pro- environmental attitude and (6) is the highest level of response for pro- environmental attitude. 15 items of (NEP) Scale developed by Dunlap and Van Liere has been applied to measure citizen's environmental attitudes. In this research we examine NEP scale and its reliability and validity. The eight items $(2,4,5,7,9,11,13,15)$ were worded so that agreement indicates a proecological view, and the seven $(1,3,6,8,10,12,14)$ ones so that disagreement indicates a proecological worldview. A commonly used rating scale, respondents are asked to indicate their strength of agreement with each statement.

This research was based on a five dimensional theoretical framework constructed for the index on environmental attitude. The index also included exploratory factor analysis and a reliability test for internal consistency.

Factor analysis identified four dimensions. Table 1 shows items selected for each construct that had a factor loading rate higher than 0.5. Results show that KMO was 0.71 (more than 0.5), indicating that the number of samples was suitable for factor analysis. The Bartlett test determined 1556.13, meaning the distinction of factors 
Table 2. The averages of environmental attitude and dimensions.

\begin{tabular}{|l|c|c|c|c|}
\hline & Number of Items & Range & Mean & Std. deviation \\
\hline Environmental attitude & 15 & $29-75$ & 49 & 5.58 \\
\hline antianthropocentrism & 4 & $4-21$ & 14.11 & 2.45 \\
\hline Limits of growth & 4 & $4-22$ & 11.69 & 2.27 \\
\hline The possibility of an ecocrisis & 3 & $7-18$ & 15 & 2.37 \\
\hline The fragility of nature's balance & 4 & $4-20$ & 14.74 & 2.36 \\
\hline
\end{tabular}

was accurate and items had high root correlation with each other in one factor. Evaluation of explained variance by the first factor was 22.45 and the total explained variance was 60.53 . The rotation method was Varimax. The internal consistency in terms of reliability of items was 0.64 .

Factor analysis in this research indicated four dimensions and the factor 'rejection of exemptionalism' cited in Dulap et al., (2000) wasn't extracted. For the factor 'citizens of Tabriz', in which humans are still subject to the laws of nature, was related to the dimension of anti anthropocentrism. Also, the factor 'will humans eventually learn enough about how nature works to be able to control it', was found to be related to the 'with limits of growth' dimension. Human ingenuity will ensure that humans will not make the earth uninhabitable, this was also associated with the possibility of an eco-crisis dimension.

Factor analysis was important because Dunlap et al (2000) suggested that researchers might interpret their results in different ways. The extraction of different dimensions occurs because of differences in context, worldview, culture, society, economics and even politics. It is clear that the NEP scale is a useful instrument to measure environmental attitude but it isn't an inflexible scale. However the reliability of these items and this scale is obvious.

\section{Descriptive Results}

In the research sample there were 339 men and 343 women from a total of 682 . The dependent variable of the research was environmental attitude that was evaluated on the Likert scale. The score of 15 was the lowest level of pro-environmental attitude and a score of 90 indicated a very strong pro-environmental attitude in respondents.

Education was evaluated in terms of level of education, respondents' habits related to reading books and newspapers, use of the Internet and access to news media. Economic evaluations were made according to monthly income, type and number of cars and houses and bank account.

The average of evaluations for environmental attitude among citizens of Tabriz was 49, a medium average. This suggests that the citizens of Tabriz consider the environment as somewhat valuable and somewhat negligible. The average of evaluations for the possibility of an eco crisis was 15 , that is a high average and it seems that citizens think that there are environmental crises on global and local levels and that human action leads to environmental crises. It was also pointed out that the Drying up of Lake Urmia is a serious crisis in the region and that the problem needs to be addressed. The average evaluation for the fragility of nature's balance was 14.74 and the average of evaluations for anti anthropocentrism was 14.11, these evaluations are medium average. The average of evaluations for limits of growth was 11.69, lowest average. These results show that citizens think there aren't limitations for growth. Some of the subjects pointed out that Iran is a rich country with an unlimited wealth of natural resources. Table 2 shows that average evaluations of environmental attitudes and other dimensions.

\section{Hypotheses Test}

Environmental attitude and gender. differences among averages of environmental attitudes based on gender were measured by the T-Test. Results show significant difference between male and female attitudes toward environment and this difference was significant (sig. 0.007). The average score for women (average of 49.7) was higher than that for men (average 48.5). Also, the average of evaluations for anti anthropocentrism among women was higher than that among men; women considered that plants and animals have as much right as humans to existence and that humans have no inherent right to undermine the earth's natural resources or to modify the natural environment to suit their own needs. But no differences were determined between other dimensions and attitudes to the environment. The results are presented on Table 3.

Environmental attitude and education: The Pearson Correlation was used to measure the relationship between environmental attitude and education. The results showed that there was a significant relationship between 
Table 3. The result of the T-test for environmental attitude and gender.

\begin{tabular}{|c|c|c|c|c|c|}
\hline Dependent variable & Gender & Mean & df & $\mathbf{t}$ & Sig. \\
\hline Environmental attitude & $\begin{array}{l}\text { Women } \\
\text { men }\end{array}$ & $\begin{array}{l}49.7 \\
48.5\end{array}$ & 679 & 2.7 & .007 \\
\hline Limits of growth & $\begin{array}{c}\text { Women } \\
\text { men }\end{array}$ & $\begin{array}{l}9.5 \\
9.8\end{array}$ & 679 & -1.8 & .07 \\
\hline antianthropocentrism & $\begin{array}{c}\text { Women } \\
\text { men }\end{array}$ & $\begin{array}{l}12.3 \\
11.8 \\
\end{array}$ & 677 & 2.4 & .03 \\
\hline The possibility of an ecocrisis & $\begin{array}{c}\text { Women } \\
\text { men }\end{array}$ & $\begin{array}{l}12.6 \\
12.7\end{array}$ & 679 & -0.4 & .61 \\
\hline The fragility of nature's balance & $\begin{array}{c}\text { Women } \\
\text { men }\end{array}$ & $\begin{array}{l}2.2 \\
2.5\end{array}$ & 680 & 0.3 & .72 \\
\hline
\end{tabular}

Table 4. Pearson Correlation Results.

\begin{tabular}{|l|c|c|c|c|}
\hline & \multicolumn{2}{|c|}{ Education } & \multicolumn{2}{c|}{ Economic properties } \\
\hline Dependent variable & Sig. & Correlation & Sig. & Correlation \\
\hline Environmental attitude & .000 & 0.33 & .008 & 0.11 \\
\hline antianthropocentrism & .002 & 0.13 & .54 & 0.02 \\
\hline Limits of growth & .023 & 0.09 & .12 & 0.06 \\
\hline The possibility of an ecocrisis & .001 & 0.13 & .61 & 0.02 \\
\hline The fragility of nature's balance & .001 & 0.14 & .06 & 0.08 \\
\hline
\end{tabular}

environmental attitude and education (sig. 0.00). This relation was direct, when the level of education was higher, then the attitude to the environment became supportive and educated people showed more concern about the environment.

Also, there was a significant relationship between education and other dimensions of attitudes to the environment. A higher level of education determined that people had an understanding of the limits of growth and the possibility of an eco crisis. Anti anthropocentrism and the fragility of nature's balance are factors that had a significant relationship with environmental attitude. These results imply that environmental attitude was related to knowledge and understanding.

Environmental attitude and economic properties: The Pearson Correlation was used to measure the relationship between environmental attitude and economic prosperity. The results showed a significant relationship between environmental attitude and economic prosperity (sig. 0.008). This relation was direct, when properties increase consequently environmental attitude became supportive. This was because richer people live in cleaner places with clean air, water, soil in places that are generally more green. They also have access to more information and are more familiar with debates presented in the media. Furthermore, it is possible that rich people imagine having a supportive attitude toward the environment as a matter of dignity. Results are show in Table 4.

\section{Multiple Regression Analysis}

In multiple regression analysis, the dependent variable was that of environmental attitude and independent variables were those of economic prosperity, education and gender. The method of regression was stepwise. Multiple regression analysis indicated that education explained eleven percent of variance of evaluations for environmental attitude. The Beta coefficient of education was 0.33 . Results has shown that education has a strong effect on environmental attitude but gender or economic property does not effect environmental attitudes. Table 5 shows the results.

\section{CONCLUSION}

The relationship between humans and the environment during human life has had many ups and downs. Nature has sometimes been considered as a source of spiritual inspiration and sometimes as a source of material need, it has also stimulated much wonder for human existence, encompassing hopes and fears for the future Environmental crises at the global level indicate an attitude of relative indifference to the environment by public authorities and officials, to such an extent that public welfare has been placed at risk. However the essential 
Table 5. Model Summary and Coefficients.

\begin{tabular}{|c|c|c|c|c|}
\hline & Model & $\mathrm{R}$ & R Square & Adj R Square \\
\hline & 1 & 0.33 & 0.114 & 0.113 \\
\hline Model & $\begin{array}{c}\text { Unstandardized } \\
\text { Coefficients B }\end{array}$ & $\begin{array}{c}\text { Standardized } \\
\text { Coefficients Beta }\end{array}$ & $\mathrm{t}$ & Sig. \\
\hline constant & 40.8 & & 45.7 & .000 \\
\hline Education & 0.069 & 0.33 & 8.6 & .000 \\
\hline
\end{tabular}

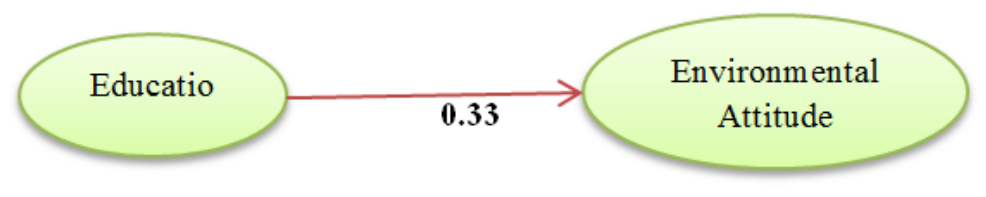

Figure 1. Regression model.

question is that of, what is the ultimate utility of inhabitants of the earth? The irregular use of natural resources to provide human's material needs or care in terms of human consumption of nature in order to maintain a sustainable environment? This question can only be answered by research on people's attitudes, worldviews and behavior.

Some solutions to environmental crises have emphasized the following considerations: careful use of natural resources, sustainability or ecological modernization, control of population growth; consumption and productivity in societies, control of industrial and non-recyclable waste, respect for nature rather than the instrument of attitude, people's level of education and the creation of environmental awareness. Among these solutions what's more basic is the attitude of people to the environment that is the major factor affecting predictions of individual behavior.

The main purpose of this research was to identify and consider environmental attitudes in association with the scale of the new environmental paradigm (NEP). The exploratory factor analysis indicated that the NEP scale in this research had four dimensions, while other research, Dunlap et al., (2000) indicated five dimensions. Rejection of the dimension exemptionalism was determined and its three items showed high root correlation with other dimensions. The three items were as follows; despite our special abilities, humans are still subject to the laws of nature and this is related to anti anthropocentrism; 'humans will eventually learn enough about how nature works to be able to control it is related to 'growth has a limit' and 'human ingenuity will ensure that we do not make the earth uninhabitable' is related to 'the possibility of an eco crisis'.

Also investigated in this study was the relationship of the environmental attitude of citizens of Tabriz within the context of the factors of gender, education and economic prosperity. The results demonstrated that the average of evaluations for environmental attitude of citizens was determined as medium. This means that the citizen's had a somewhat protective attitude to the environment. The citizens had some degree of anti-anthropocentric attitude, in that evaluation showed that they think humans are not the only species inhabiting the earth and that plants and animals have rights to existence comparable to those of humans. This conclusion is compatible with the principal assumptions of the NEP scale; that citizens consider the human impact on the environment and that environmental crises are possible. This awareness can be the product of mass media and the free flow of information.

The relationship between economic prosperity and environmental attitude was significant. Also, significant was the relationship between education and environmental attitude. Educated people had a more supportive attitude toward the environment. This result suggests the importance of knowledge and literacy in environmental issues. However, the survival of humanity in future decades according to Capra (2008), will depend on our ecological literacy - our ability to understand the basic principles of ecology and to live accordingly. This means that eco literacy must become a critical skill for politicians, business leaders and professionals in all spheres of society and this should be the most important part of education at all levels - from primary and secondary schools to colleges, universities as well as continuing education and professional training.

This research has sought to determine what factors are related to the environmental attitudes and which sociodemographic factors; gender, education and economic property tend to have a positive influence on environmentalism. Also environmental knowledge changes environmental attitudes, and environmental attitudes influence environmental behaviors. Likewise, women are more likely to hold environmental attitudes than men. Highly educated respondents are more likely to hold environmental attitudes than those with less education. 


\section{REFERENCES}

Anderson, Mark. W., (2012). The New Ecological Paradigm, NEP Scale. The Berkshire Encyclopedia of Sustainability: Measurements, Indicators and Research Methods for Sustainability, pp. 260-262.

Azjen, I. and Fishbein, M., (1980). Understanding Attitudes and Predicting Social Behavior. Englewood Cliffs. NJ: Prentice Hall.

Capra, F. (2008). The New Facts of Life: Linking Food, Health, and the Environment. [online] Available at: http://www.ecoliteracy.org/publications/fritjof_capra_facts.html.

Catton, W.A. and Dunlap, R.E., (1978). Environmental Sociology: A New paradigm. The American Sociologists, vol. 13, pp. 41- 49.

Dunlap, Riley. Van Liere, Kent. Mertig, Angela \& Emmet Jones, Robert (2000). Measuring Endorsement of the New Ecological Paradigm: A Revised NEP Scale. In Journal of Social Issues, vol. 56, no. 3, pp. 425-442.

Fishbein, M., \& Ajzen, I. (2005). The influence of attitudes on behavior. The handbook of attitudes, 173-222.

Franzen, A. \& Meyer, R. (2008). Environmental Attitudes in Cross-National Perspective: A Multilevel Analysis of the ISSP 1993 and 2000. European Sociological Review, Published by Oxford University Press.

Huber, J. (2002). Environmental Sociology in Search of Profile. Soziologie, Forum der Deutschen Gesellschaft Fur Soziologie, Heft 3, pp. 23-36.

Humphrey, C. Lewis, T. and Buttel, F. (2002). Environment, Energy and Society: A New Synthesis, Wadsworth Publacation.

Kaiser, F., Wolfing, S. and Fuhrer, U. (1999). Environmental Attitude and Ecological Behavior. Journal of Environmental Psychology, vol 19.

Kollmuss, A. and Agyeman, J. (2002). Mind the Gap: why do people act environmentally and what are the barriers to pro-environmental behavior? Environmental Education Research, vol. 8, no. 3, pp. 239- 260.

Kopnina, H., (2011). Qualitative Revision of the New Ecological Paradigm (NEP) Scale for children. International Journal of Environmental Research, Tehran University, Iran: vol. 5, no. 4, pp. 1025-1034.

Maleki, A., and Karimzadeh, S. (2011). A survey of relationship between the environmental attitudes and environmental knowledge and energy consumption behavior among citizens of Urmia, West Azerbaijan, Iran. International Journal of Social Sciences and Humanity Studies, 3 (1), 27-37.

Rokeach, M. (1968). Beliefs, attitudes and values, San Francisco: Jossey- Bass.

Slavin, B. (2013). Iran Faces Environmental Crisis. Al-Monitor, [online] Available at: http://www.almonitor.com/pulse/originals/2013/08/environment-pollution-iran-water.html\#ixzz4ULkOf0ao.

Stets, J. and Biga, Ch. (2003). Bringing Identity Theory into Environmental Sociology. Sociological Theory. New York, pp. 398- 423.

Stern, P.C., Dietz, T., Kalof, L., and Guagnona, G.A. (1995). Value, Beliefs and Proenvironmental Attitude Formation toward Emergent Attitude Objects. Journal of Applied Social Psychology, 25, pp. 1611-1636.

Stern, P.C., Young, O.R. and Druckman, D. (1992). Global Environmental Change: Understanding the Human Dimensions, Washington, DC: National Academy Press.

Tuna, M. (2004). Public Environmental Attitude in Turkey. 3rd Global Conference Ecological Justice and Global Citizenship, Charles Darwin University, Australia, [online] Available at: http://www. inter-disciplinary. net/ptb/ejgc/ejgc3/tuna\% 20paper.

Usui, M., Vinken, H. and Kuribayashi, A. 2003. Pro-environmental Attitudes and Behavior: an International Comparison. Human Ecology Review, vol 0, no 1. 